\title{
DE LA METAFÍSICA AL PENSAMIENTO ABISAL: REFLEXIONES SOBRE LA HISTORIA DEL SER EN MARTIN HEIDEGGER
}

\author{
Alejandro Valenzuela A. \\ Universidad de Chile \\ aovalenz@gmail.com
}

\begin{abstract}
RESUMEN / ABSTRACT
Este artículo constituye una detallada exploración de la profunda transformación experimentada por el concepto de "historia" a la luz del salto intentado por Martin Heidegger desde la metafísica hacia el ámbito del pensamiento (del Ser). En un primer momento, la exposición sigue de cerca la lógica interna del pensar metafísico para demostrar luego con ello el carácter necesariamente metafísico de sus dos maneras de "procesar" la historia: la filosofía de la historia y la historiografía. Desde ahí, el artículo avanza hacia un modo radicalmente nuevo de entender la naturaleza de la historia: aquello que Heidegger llama "el otro inicio".
\end{abstract}

Palabras Clave: historia del ser, historiografía, filosofía de la historia, metafísica, 'el otro inicio'.

\section{FROM METAPHYSICS TO ABYSSAL THINKING: REFLECTIONS ON the History of BeING of Martin HeIDEGGER}

This article presents a detailed exploration on the profound transformation set to work on the concept of 'history' by Martin Heidegger's risky leap from metaphysics into the domain of thinking (the thinking of Being). At first, the exposition follows closely the inner logic of metaphysical thinking in order to prove then the necessarily metaphysical position held by its two ways of processing history: the philosophy of history and historiography. From this point, the article moves further on to consider a radically new way of grasping the nature of history: that which Heidegger calls "the other beginning".

KEYWORDS: The history of Being, historiography, philosophy of history, metaphysics, "the other beginning". 
Das System ist der Geist gewordene Bauch.

Theodor Adorno

El dominio de la metafísica -su límite interno, su ámbito de reflexión- está determinado en todo momento por el alcance de la pregunta-guía (die Leitfrage), por el modo en que ésta pregunta por el ser. Al preguntar por el ser "desde" y "en dirección a" el ente, la pregunta-guía (de la metafísica) presupone una toma de posición o una cierta interpretación del ser-desde luego, una interpretación metafísica-, y en tal medida ella prefigura necesariamente toda respuesta posible, todo intento por colmar la falta que la ha puesto en marcha. La metafísica tiene una inscripción inaugural: la interpretación de Platón del ser como presencia - o, si se quiere, como comparecencia. De acuerdo con Heidegger, en la filosofía de éste, la experiencia de la aletheia que había dado origen al pensamiento de los primeros filósofos griegos empezaba ya a desgastarse, a perder su fuerza originaria. Sin lugar a dudas, la marca más evidente de este desgaste está en el hecho de que Platón no consigue experimentar el ocultamiento que le es propio al no-ocultamiento, la no-verdad que le es esencial a la verdad (Heidegger 2007, p. 139). Si en el pensamiento de Platón la aletheia empieza a corresponder a lo ente -esto es, que lo ente mismo pasa a ser lo no-oculto, lo verdadero-, el ocultamiento se convierte correlativamente en mera ausencia del ente, en una nada. Así, por medio de la interpretación del ser como presencia, verdad y realidad acaban equiparándose. El ente, en consecuencia, es lo que ahora da la medida: puesto que es innegable que él y solo él es, todo el edificio de la metafísica ha de construirse sobre la base de la existencia verdadera del ente. Este es el comienzo de la metafísica, o, lo que es equivalente, el comienzo de la filosofía como nihilismo. Nihilismo -según la concisa definición de Heidegger-: el hecho de que del ser, que nunca es el ente, no hay nada. Para la metafísica solo hay ser desde el ente: como su "que-es" (existencia) y su "qué-es" (esencia). Puesto que su aparición se debe precisamente a la represión de la diferencia ontológica, la metafísica no sabe y nunca podría saber nada de la originaria inter-sición del ser frente al ente. Todo lo que la metafísica sabe (del ser) del ente lo sabe precisamente porque del ser no sabe nada. Este no-saber que posibilita su saber ha de permanecer oculto para ella misma-de lo contrario, se suprimiría en tanto que metafísica. Como señala Heidegger en el último capítulo del Nietzsche -en la traducción de Eduardo Carrasco-, "[a]quella historia del ser que es conocida como Metafísica, tiene dentro de su esencia, que acontece (sich ereignet) un "salir fuera" (Fortgang) a partir del inicio. En este "salir-fuera", el ser se licencia en la entidad y deniega el claro (Lichtung) de la inicialidad del inicio" (Heidegger en Carrasco 2007, p. 155). Esta negación del claro -el olvido del ser- es la otra cara del predominio del ente en la época metafísica, el necesario revés de aquel anverso en que el ente campea como la única verdad. Pero la metafísica tiene mala memoria: no solo ha olvidado al ser sino que también ha olvidado el olvido mismo. Otra vez: nihilismo - del ser no hay nada.

Que el ente es no resulta en absoluto problemático para la metafísica. El ente existe: es decir, el ente es. La verdadera pregunta para la metafísica pareciera centrarse 
más bien en el qué-es, en lo que funciona como causa o fundamento del ente. En este sentido, la filosofía se convierte desde Platón en la búsqueda del "por qué" originario que explica al ente. En este punto emerge con fuerza el movimiento de trascendencia que le es propio a la tradición metafísica: un ir más allá del ente para luego volver a él y asegurarlo desde su fundamento. Esto es lo que ocurre con Platón: la estabilidad de la existencia de un ente cualquiera depende de su grado de participación de la Idea que funciona como su causa o modelo originario. El ser aquí ha sido concebido en todo sentido bajo el modo de la presencia del ente: en la medida en que las Ideas están libres de la corrosión del tiempo, ellas son el modelo de lo que todo ente ha de aspirar a ser: una presencia estable. Para Platón, en consecuencia, el ser cumple el papel de la entidad del ente, y es precisamente el grado de proximidad a esa entidad lo que determina el grado de existencia de éste -ídolo, fantasma, etc. Si Platón insiste sobre la presencia en cuanto mostrarse del aspecto (Idea, Esencia), Aristóteles pondrá luego el acento sobre la presencia bajo la forma de lo que mora en cada caso en el demorarse del aspecto (Energeia, Existencia). Esta doble determinación de la presencia es la piedra fundacional de la metafísica (Heidegger 2000, p. 335). Más tarde en la historia de ésta, sin embargo, con la traducción latina -o mejor: la interpretación latina- del concepto griego de energeia como actualitas, la filosofía occidental experimenta un giro de la mayor importancia. Como explica Heidegger, ahora el ente ya no es porque se demora en la presencia (interpretación griega del ser), sino más bien porque se constituye como "realidad efectiva", esto es, como lo efectuado en un efectuar. Indudablemente, el ser es pensado aún desde el ente, es decir, como presencia, pero la diferencia estriba en que esta vez el acento cae sobre el hecho de que ese ente ha sido producido, de que él ha sido efectuado por otro ente. Con esta transformación del ser del ente, la metafísica alcanza un nuevo estadio en su despliegue, una expansión del ámbito histórico abierto por el olvido del ser.

Al considerar el ser como ser-efectuado, el concepto de actualitas reúne hasta cierto punto los dos aspectos de la presencia propios del comienzo de la metafísica. Lo que es, lo que existe, es porque ha sido causado, porque ha sido efectuado desde alguna parte. Evidentemente, la pregunta metafísica por el qué del ente se orienta desde entonces hacia la búsqueda del ente o del principio que estaría detrás de la efectuación de la realidad efectiva o del conjunto de los entes. Como señala Heidegger, se trata de saber ahora qué voluntad o qué ente es el que da la medida, qué es lo verdaderamente existente que determinará a la totalidad de los otros entes. "El ente es lo real (das Wirkliche). La realidad (Wirklichkeit) salva su esencia en el realizar (Wirken), el cual como propia esencia, consigue (erwirken) que la voluntad sapiente se vuelva la eficacia (Wirksamkeit) que da la medida. La realidad traslada su esencia a la multiformidad de la voluntad" (Heidegger en Carrasco 2007, p. 162). En esta escena metafísica, el ser no es más que un juego (de poder) entre entes: la pregunta es cuál de ellos será el que imponga su valoración, su propia medida. Heidegger señala tres entes que históricamente se han desempeñado como "entes fundamentales": Dios, la naturaleza y el hombre. Por ahora, me detendré solo en el último de éstos, pues es el ente que abre el camino para la filosofía moderna y también para aquello que específicamente me interesa pensar en ella: la metafísica como sistema o como saber total de los entes. La razón 
por la cual el hombre puede hacer de fundamento en relación con la realidad es porque él se revela a partir de la filosofía de Descartes como una existencia necesaria-Dios cumplió antes este papel-, o al menos necesaria en la medida en que es la única realidad sobre la cual no puede dudar quien decide someterlo todo a la duda metódica: is qui cogitat, non potest non existere, dum cogitat-escribió famosamente Descartes. Tal es el postulado básico de la filosofía moderna: si existe un mundo, una realidad, entonces necesariamente debe existir con anterioridad -si no temporal, al menos lógica- el observador para o ante el cual ese conjunto de entes se muestra. El hombre, en tanto que nuevo subjectum, es la presencia constante por excelencia-él siempre ha estado ahí, bajo la realidad, determinando el modo en que aparece todo lo que aparece. Por este motivo, solo con la metafísica de la subjetividad empieza de manera definitiva la objetivación incondicionada y completa de todo lo que es -objetivación total que la tradición metafísica previa "prepara" pero que en ningún caso hubiera podido cumplir. Este nuevo aseguramiento del ente no es posible más que al interior de la metafísica de la subjetividad.

Sin embargo, este dominio del ente resulta engañoso en lo que se refiere al afianzamiento de la esencia del hombre. Si bien éste ha sido nombrado por la metafísica moderna como el "legislador de lo real" - esto es, como el ente que otorga la medida para todos los otros entes, como el garante de la objetividad de todo objeto (Kant)-, ese nombramiento supone al mismo tiempo una caída del hombre en medio del ente, un restarse por completo de su (olvidada) pertenencia al ser. Heidegger es absolutamente enfático en este punto:

Representando el ser en el sentido del ente en cuanto tal, [el hombre] cae en el ente para, quedando a su merced, erigirse a sí mismo como el ente que representandoproduciendo se apodera del ente en cuanto algo objetivo. El hombre, desde sí, pone en seguridad su esencia en medio del entre frente y a favor de éste. El aseguramiento en el ente intenta llevarlo a cabo por medio de un orden completo de todo el ente en el sentido de un aseguramiento planificado de su existencia consistente... (2000, p. 307).

Solo en el ámbito de la representación puede la metafísica entrar en su época propiamente sistemática. En este recorrido, es central captar que el sistema tiene por condición de posibilidad la postulación del hombre como sujeto reflexivo: la totalidad de los entes solo puede ser asegurada en la medida en que el fundamento ha sido a su vez asegurado, en que éste se ha captado a sí mismo en cuanto fundamento. Medularmente, la relación del sujeto moderno con la realidad es especular: puesto que él se sabe como lo que determina el modo de aparecer (la objetividad) del ente (el objeto), como el ente condicionante que se anticipa y determina de antemano el ser de todo otro ente, su saber sobre la realidad no podría ser otra cosa que un saber autorreflexivo relativo a las determinaciones que él mismo le impone a los entes con el fin de constituirlos. Como señala Heidegger, el sistema solo puede desarrollarse con la concepción del ser del ente como unificación anticipatoria (1996/1997, p. 53). No hubiera podido darse una metafísica sistemática en la filosofía griega o medieval pues en ellas no existía la posibilidad de elaborar una sistemática de lo incondicionado que condiciona. Sistema 
y totalidad solo tienen lugar en la historia del pensamiento tras el surgimiento del sujeto $^{1}$. El sujeto ejerce su acción sobre lo real bajo la forma de un representar o de un aprehender mediante "conceptos": en cuanto ente incondicionado, él tiene los títulos para tomar decididamente por asalto la totalidad de lo ente (Heidegger 2010, p. 174). Nada podría oponerse más a este modo de comportarse en medio del ente que aquel "demorarse en la presencia" propio del pensamiento griego, aquel "dejar yacer al ente para que se muestre desde sí" al que me referí hace un momento. En el contexto de la metafísica moderna, la presencia no es ni nunca podrá ser ya un tranquilo reposar en sí del ente, sino el efecto o el resultado del obrar de un ente que ha sido proyectado como ontológicamente prioritario: el propio sujeto. El hombre en su caracterización moderna es quien "postula" el mundo, quien lo representa o pone frente a él. El obrar del sujeto es tético, fundante, ponente. Su voluntad -la espontaneidad que le es propia en cuanto incondicionado que condiciona- construye el mundo, dispone de él, lo transforma a su antojo. Naturalmente, Marx nunca supo nada de esto -nunca supo que su llamado a abandonar la interpretación (metafísica) del mundo para promover su transformación en la praxis era tributaria en realidad de una interpretación metafísica del ser del ente. En la época del sujeto, lo propio del hombre es "humanizar" el mundo: hacerlo a su medida, modelarlo a la luz de las formas que su razón proyecta. El sujeto es ante todo voluntad -voluntad que obra disponiendo fines, trazando cursos posibles de acción, determinando medios acordes a las metas que se ha impuesto.

Dado que el sujeto desea transformar la realidad para hacer más segura su existencia en medio del ente, su obrar está marcado en todo momento por el apetito. En este sentido, la voluntad del sujeto existe como un conatus, como la propensión o inclinación a realizarse a sí misma en cuanto garante de la consistencia de lo real. De ahí el epígrafe de Adorno que he elegido para abrir este ensayo: "[e]l sistema es el vientre hecho espíritu" (2008, p. 32). Anticipándose a la realidad con el fin de garantizar su inteligibilidad o su dominio sobre ella, el sujeto de la metafísica anula con el mismo movimiento a esa realidad en su singularidad. En cuanto apetito, el sujeto moderno es ciego a la donación de lo real. Su señorío, escribe Heidegger, es ilusorio. O, mejor aún, se trata de un señorío que se ha vuelto esclavo de su propio señorío: "El tener descrito es inauténtico, porque la aparente libertad del disponer y del emplear es, en el fondo, una servidumbre bajo la falta de orden y concierto y la contingencia de las

1 Indudablemente, la unidad (y necesidad) de esta constelación de conceptos - subjetividad, sistema, totalidad, verdad- tiene en la obra de Hegel su formulación más extrema. Recuérdese, por ejemplo, el siguiente pasaje de la Fenomenología: "Lo verdadero es el todo. Pero el todo es solamente la esencia que se completa mediante su desarrollo. De lo absoluto hay que decir que es esencialmente resultado, que solo al final es lo que es en verdad, y en ello precisamente estriba su naturaleza, que es la de ser real, sujeto o devenir de sí mismo" (16). Un sujeto, para Hegel, es una conciencia que ha logrado recorrer o atravesar todo su saber sobre la realidad, es decir, una conciencia que ha llegado a conquistarse a sí misma como fundamento de lo real. La verdad, en consecuencia, solo puede ser un resultado: el estadio final es la certeza absoluta (la ciencia), el saber que emerge una vez que ha sido asegurada la totalidad de los entes. 
carencias y las necesidades. Aquel tener es, en el fondo, un ser-tenido por aquello que seduce al empleo de la posesión" (Heidegger 2007, p. 203). La consagración metafísica del "tener" - un "tener" con respecto al cual el sujeto es ejemplar en la medida en que él es quien estaría en plena posesión de sí- produce simultáneamente una profunda inseguridad: ahí donde todo se ha convertido en un disponer de los entes al antojo de cada cual, el hombre padece (inconscientemente) la pérdida de su propia esencia -su pertenencia al ser. Los sistemas de la metafísica moderna no son otra cosa que una semblanza del orden, un intento por establecer algún grado de arraigo o de seguridad en una situación que es fruto del más profundo desarraigo ${ }^{2}$. En último término, todo nihilismo es necesariamente inseguro: al no haber nada del ser, la soberanía exclusiva del hombre se consume en ella misma, se mira en un espejo que solo es capaz de devolverle la imagen de su propio rostro.

Llevemos por un momento la discusión sobre la metafísica del sujeto al terreno de la historia. En efecto, ¿qué ocurre con la concepción de la historia en el tiempo (histórico) de la verdad como verdad del sujeto? "[E]l comienzo de la a-historicidad ya [está] aquí" (p. 59), escribe Heidegger en sus Contribuciones. Evidentemente, esta a-historicidad es el fruto del aparente triunfo del ente frente al ser en el límite extremo de la metafísica moderna -la maquinación. Si solo hay historia como historia del ser, el acontecimiento del olvido del ser necesariamente ha de afectar el modo en que los modernos comprendemos -o más bien no comprendemos- la historia. Según creo, esta (in)comprensión asume dos formas en la época moderna: la filosofía de la historia y la historiografía (la historia como ciencia). En cuanto a la primera, es incuestionable el grado en que ella depende de la concepción de la metafísica como filosofía sistemática. Basta una mirada de superficie para percatarse de que la filosofía de la historia es en realidad la lógica del sistema volcada sobre el campo de la historia. Para una concepción "estructural" -el término es de Paul Ricoeur- de la historia de la filosofía,

2 Desde una perspectiva diferente, Adorno formula en su Dialéctica negativa una asociación entre "sistema" e "inseguridad" que, a mi juicio, guarda cierta relación con la concepción de Heidegger que he estado revisando. "La ratio burguesa emprendió la producción a partir de sí del orden que desde fuera había negado [el orden feudal]. Pero éste deja de ser tal en cuanto producido; es, por tanto, insaciable. El sistema era tal orden generado de forma absurdo-racional; algo puesto que se presenta como ser en sí. Tuvo que trasladar su origen al pensar formal separado de su contenido; no de otro modo podía ejercer su dominio sobre el material" (Adorno 2008, p. 31). Si bien Adorno plantea en estas líneas una lectura materialista del origen de los sistemas modernos que nada tiene que ver con el modo en que Heidegger piensa la historia, de todos modos me parece sugerente el paralelo entre ambos pensadores en lo relativo al señorío ilusorio de la metafísica del sujeto. Por supuesto, este carácter ilusorio proviene, de acuerdo con Heidegger, del hecho de que el metafísico moderno no sabe que ha sido el ser quien le ha otorgado el poder con el que cree dominar la realidad. Más adelante abordaré este carácter inesencial que le es esencial a la metafísica. De cualquier manera, es importante enfatizar que no por ser ilusorio el señorío del sujeto resulta "falso". En realidad, su señorío es completamente verdadero -él es una forma histórica de la verdad al interior de la (desconocida) historia del ser. 
cada pensador o cada filosofía particular no es más que un momento al interior de una suerte de filosofía única que estaría configurándose a través de ellas. En este aspecto del asunto, el modelo es, por cierto, otra vez Hegel. La aventura del Espíritu en la historia representa precisamente un movimiento de este tipo: en él, nada o casi nada queda de la singularidad o irreductibilidad de los pensadores del pasado con respecto al presente, pues cada uno de ellos ha sido asumido como un particular dentro de una suerte de saber universal que solo saldría a la luz una vez que el recorrido del Espíritu los hubiese incorporado a su propia verdad absoluta en tanto que momentos de sí. Ahora bien, es importante poner de relieve que lo que surge en esta asunción final de todo el recorrido -la verdadera ciencia, el saber absoluto- depende en todo momento de la categoría de sujeto, o, mejor dicho, que éste es su necesario correlato. Es la verdad del sujeto - no en el sentido de la verdad como mera opinión del sujeto, sino del sujeto mismo como verdad- lo que es "puesto" en este caso en el lugar de la historia. En este punto nos encontramos nuevamente con el problema de la ceguera: "[e]l progreso de un filósofo en su propio sistema -anota Ricoeur, un atento lector de Heidegger- lo vuelve cada vez más ciego a la historia, no disponible para otro" (2015, p. 63). ¿En qué consiste esta "no disponibilidad" del metafísico sistemático en relación con la historia? ¿De dónde surge tal actitud y en qué medida ella es una condición insuperable para la propia metafísica? Todas las filosofía de la historia de la época moderna tienen como presupuesto el hecho de que entre la historia y la razón humana existe una suerte de pacto o de pertenencia mutua: a saber, que la historia en último término no sería sino la historia del desarrollo de la razón o la conciencia, y que esta última, a su vez, tendría lugar solo como historia, es decir, como desarrollo o expansión de sí misma a lo largo del tiempo -en otras palabras, que existiría solo como tarea o proyecto. En este pacto está contenida toda la ambigüedad de la relación del metafísico con la historia. La filosofía de la historia "borra" la historia porque solo la encuadra desde la verdad en la que ella misma está situada. Si para la metafísica moderna la verdad es el sujeto o la conciencia, entonces la marcha de la historia necesariamente ha de ser el desarrollo gradual de esa conciencia a lo largo del tiempo. Pero es evidente que el concepto de sujeto es portador de una inscripción histórica específica, es decir, que el sujeto no siempre estuvo ahí -desde luego, no lo estuvo entre los griegos o en el pensamiento medieval. En este sentido, las filosofías de la historia son ciegas para toda verdad que no sea la verdad que las ha constituido. Ellas mismas se desconocen -desconocen la historia que ha hecho de su verdad una verdad histórica: la historia del ser. Esta, según creo, es la médula de la "no disponibilidad" a la que se refería Ricoeur: una no disponibilidad para la verdad como historia y para la historia como verdad. Eduardo Carrasco explica con claridad esta situación: "En la historia de la filosofía no puede establecerse ni un progreso ni una regresión, pues no hay ningún criterio a-histórico que atraviese las distintas épocas, permitiendo así su comparación [...] siendo la verdad misma histórica, no hay nada que se escape a esta condición” (2007, p. 131).

El segundo camino que los modernos han asumido para "atrapar" lo histórico es lo que Heidegger ha llamado historiografía, o la aprehensión científica del pasado. Como en toda ciencia moderna, lo que está en juego en la vuelta historiográfica sobre el pasado es una eventual objetivación total de lo ya acontecido, un trazado riguroso 
del conjunto de relaciones que tuvieron lugar al interior de la totalidad de entes que conforman el campo de la ciencia de la historia: los entes históricos. Leopold von Ranke, uno de los fundadores de la moderna historia científica, explica de la siguiente manera el alcance de su ámbito de estudio: “...la atención del historiador deberá enfocarse, no hacia los conceptos que parezcan imperar en algunos, sino hacia los pueblos mismos que representan un papel activo en la escena de la historia, hacia la influencia que ejercen los unos sobre los otros, hacia las luchas que entre sí sostienen, hacia la trayectoria que desarrollan dentro de estas relaciones pacíficas o guerreras" (1948, p. 519). En efecto, ¿qué otra cosa podría ser la historia aparte de lo que ocurre sobre la "escena de la historia", de aquel ir y venir de los actores que se mueven dentro de la arena histórica con el fin de obtener lo que sea que se hayan propuesto obtener? Difícilmente podría negarse que el historiador trabaja con entes históricos, pero igualmente difícil sería negar que el fenómeno mismo de la historia necesariamente se le escapa de las manos. En realidad, lo que el historiador jamás podría llegar a captar es el carácter propiamente histórico de eso que él llama la "escena de la historia", aquella "historia de fondo" - dentro de poco hablaremos sobre la pregunta que va al fondo (die Grundfrage)- que ha permitido el surgimiento de ese ámbito específico que para él se ofrece como el lugar donde se manifiestan los entes históricos. En la medida en que el espacio de la historia con el que la historiografía trabaja ha sido abierto de antemano por la historia (del ser), resulta evidente que el fenómeno mismo de la historia (originaria) se presenta como una suerte de punto ciego o como un impensable para todo aquel que se posicione al interior del ámbito limitado de la historiografía. Así, la paradoja ante la cual nos pone Heidegger no podría ser más sorprendente: lo que entendemos por labor historiográfica es en realidad el fruto de una pérdida de la historia. Para el filósofo alemán, con el olvido del ser

...el ente en cuanto tal, y especialmente en la época del dominio de la inesencia del nihilismo, cae en lo ahistórico. Signo de ello es la emergencia de la historiografía, que pretende ser la representación determinante de la historia [...] como si las representaciones historiográficas de la historia pudieran, con una generalización suficientemente amplia, proporcionar la determinación de la esencia de la historia (2000, p. 313).

Ranke, quien defendió programáticamente un encuentro directo con los hechos del pasado contra todo orden o esquema metafísico de aprehensión preestablecida, fue de modo inconsciente uno de los adalides modernos de la tradición metafísica, de aquella tradición nihilista que se instala en medio del ente o de la realidad positiva sin prestar oídos al incesante silencio histórico del ser.

Intentos como el de Ranke - $\mathrm{o}$, sin ir más lejos, como el del propio Nietzschepor superar el terreno de la metafísica, demuestran hasta qué punto los hábitos o la comprensión metafísica retornan del modo más inesperado. Puesto que habitamos anticipadamente en el ámbito de verdad abierto por el pensar metafísico, toda tentativa por ir más allá de él tiende a reproducir su lógica (del ente) o a expandirla. Considerar al ser como una nada o como una ilusión abstracta para favorecer en cambio el círculo de los entes, es repetir el gesto platónico que hace más de veinte siglos fundó el 
espacio de la metafísica -el espacio que interroga al ser solo desde la presencia, que equipara lo no-oculto con el ente, la verdad con la realidad. Naturalmente, todo intento metafísico por salir de la metafísica está condenado a recaer (inconscientemente) en la metafísica. En consecuencia -y esto es central para Heidegger-, la pregunta por la posibilidad de un pensar no-metafísico no puede nunca ser planteada desde la propia metafísica. "De la pregunta-guía a la pregunta de fondo no hay jamás un curso inmediato, unívoco, que aplicara la pregunta-guía una vez más (al Ser), sino únicamente un salto, es decir, la necesidad de un otro inicio" (1996/1997, p. 45). Este pasaje demuestra la dificultad inherente al asunto: preguntar directamente por el ser del Ser, es decir, repetir la pregunta-guía con respecto al Ser, es perder inmediatamente al Ser, puesto que, con un preguntar filosófico de esta naturaleza, volveríamos a hacer del Ser un ente, suprimiendo con ello la diferencia ontológica y cayendo nuevamente en el espacio de la metafísica, en el ámbito de los entes. En otras palabras, no se trata simplemente de que la metafísica sea incapaz de ver al Ser para luego interrogarlo -es decir, de una ceguera contingente que ella pudiese remediar corrigiendo el ente por el cual pregunta-, sino de una imposibilidad que está a la base de su propia fundación, de una imposibilidad que la constituye: la de ser incapaz de ver que no ve, de ser absolutamente ciega para con su propia ceguera. Por este motivo, Heidegger considera la superación (metafísica) de la metafísica como un girar en banda al interior del círculo nihilista: "Querer ir de modo inmediato en contra del permanecer fuera del ser mismo querría decir no respetar al ser mismo como ser. La superación del nihilismo así querida solo sería una severa recaída en lo impropio de su esencia, que desfigura lo que en él es propio" (2000, p. 298). Es de notar la singularísima economía de lo propio y lo impropio que rige al discurso metafísico: el esfuerzo por apresar lo que le es más propio (la impropiedad) resulta profundamente impropio en la medida en que la impropiedad es en realidad lo que le es más propio; inversamente, apostar por el camino de la impropiedad produce una escena enloquecida análoga a la primera: puesto que lo impropio es su verdadera propiedad, dirigirse directamente a lo impropio equivaldría a captarse a sí misma en toda su impropiedad y, en consecuencia, a tenerse a sí misma de un modo propio. Esta irremontable diferencia de la metafísica con respecto a sí misma, esta anómala situación que la obliga a separarse de sí como condición de posibilidad para constituirse como un fenómeno unitario, es lo que funda aquello que, con Reiner Schürmann (otro atento lector de Heidegger), podríamos concebir como el carácter trágico de la metafísica. De acuerdo con este último, el metafísico está constantemente escindido (sin saberlo del todo, por cierto, o, más bien, reprimiendo tal condición para así poder constituir su discurso) entre un "poseer" al ente en cuanto particular y una "sustracción" del ente en cuanto singular: solo hay metafísica en la medida en que este diferendo o escisión trágica es reprimido con el objeto de asegurar una explicación o una fundamentación total del ente. Lo dijimos al comienzo de este escrito: el no saber (sobre el conflicto trágico) funda el saber (de la metafísica).

A estas alturas, resulta evidente que un pensamiento capaz de superar a la metafísica en ningún caso puede ser un pensamiento tético, una contra-metafísica: esto es, una negación determinada, un poner frente a la metafísica algo así como una imagen opuesta de lo que ella es -por ejemplo, la conocida inversión del platonismo. 
Toda negación sigue presa de aquello que pretende negar. Para Heidegger, no se trata de oponerle al poder (de la metafísica) un poder igualmente fuerte, sino de "abismar" a la propia metafísica, de exponerla al impensado que en todo momento se le sustrae ${ }^{3}$. "El poder -escribe el filósofo alemán- es superado en esencia solo a través de lo no menesteroso-de poder. Solo el ser mismo, retomándose en la esencia, deja hundirse al ente, que en el no reconocido abandono del ser ha ascendido a dominio" (2003, p. 93). Desde esta perspectiva, el ser deja de cumplir el papel metafísico de ser respuesta o fundamento del ente -es decir, de ser aquello por lo que pregunta la pregunta-guía-, para transformarse contrariamente en lo más digno de pregunta, en lo abierto no domeñable. Con respecto al ser, todo "tener" queda en suspenso -en efecto, ¿cómo podría tenerse lo que abre la dimensión del tener? El pensamiento que se embarca en el camino del ser ha de decidirse a asumir insistentemente la tensión de la marcha misma -la infinitud del ser frente a la finitud del ente-, pues en este "otro dominio" solo le queda al hombre el recurso del preguntar. Sin embargo, interrogar al ser no equivale a interrogar al vacío, no es en ningún caso una nulidad; muy por el contrario, se trata de enfrentarse al des-fondamiento (Ab-grund) inexhaustible que emerge cuando el pensamiento da un salto que atraviesa la sordera metafísica - esa sordera sorda para todo lo que no sea el parloteo del ente. El ente al que Heidegger llama Dasein solo consigue hacerse cargo de su esencial pertenencia al ser cuando decide pensar lo único que merece en realidad ser pensado: “...el hombre es por primera vez hombre en cuanto llevado a lo que se sustrae, estando en camino hacia esto y, por ello, señalando lo amagado. La raíz de su esencia está en ser ese indicador. A lo que en sí, por esencia, es un indicador, lo llamamos signo. El hombre es un signo en el camino hacia lo que se sustrae" (Heidegger 2010, p.

\footnotetext{
Aunque parezca, en principio, un parangón más bien ajeno al pensamiento de Heidegger (sus escritos avalarían tal opinión), creo ver en el campo del psicoanálisis -al menos en la vertiente francesa de la teoría psicoanalítica, vertiente que, en la obra de autores como Jacques Lacan, asume un diálogo directo con el pensamiento de Heidegger- una expansión de esta singular forma de oponerse al poder. Específicamente, estoy pensando en el modo en que Lacan piensa la relación entre la histérica y el amo, que al menos en términos generales pareciera comportarse de manera similar a como lo hace el pensamiento (del ser) frente a la metafísica. La histérica, se recordará, vive atormentada por la pregunta acerca de su propia verdad -verdad que, como en el caso del ser, no puede ser nombrada debido a que ella es la que ha abierto el espacio subjetivo en el que ella habita. Por este motivo, ella decide consultar al amo (al padre, al profesor: quien sea que detente la autoridad del saber) e interpelarlo directamente con una pregunta relativa al ser. Lo que ocurre entonces, de acuerdo a Lacan, es que el saber del amo termina desfondado, castrado por la pregunta de la histérica. La histérica, sabemos, pregunta por el ser, pero el amo -o el poder-solo tiene a su disposición la lengua de los entes. No hay encuentro posible entre ambas lenguas. Es precisamente por este motivo que, en la formulación de Lacan, el analista, a diferencia del amo, ha de rechazar situarse en la posición del saber (y también, con ello, abandonar la lengua de los entes): él ha de comportarse como un eco del silencio del ser, ocupar frente al paciente la (no) posición abismática que la verdad misma tiene para el propio paciente. Solo en este sentido restringido creo ver una analogía entre la histérica y lo histórico (del ser).
} 
21). Al saltar en dirección hacia este hendimiento abismal, el hombre ha de renunciar a su señorío previo en medio del ente y salir al encuentro de eso que no admite ninguna planificación o control por parte del sujeto, de eso que se da como el puro darse: el Ser.

En su Historia del ser, Heidegger se refiere a la palabra de la filosofía abismática -a la filosofía post-metafísica abierta a la verdad de la Ereignis o del acontecimiento de pro-piación- en términos de un doble decir: como un Wider-spruch, un "decir contra", y como un Wieder-spruch, un "decir otra vez". Tanto el uno como el otro, que en último término no representan sino dos caras de un gesto común, son expresados por el filósofo alemán bajo la forma Wi(e)der-spruch. De acuerdo a éste, con estos dos prefijos quedaría caracterizado el decir del pensamiento. Esta ingeniosa fórmula, sin embargo, no nos dice por sí sola demasiado. ¿Contra qué tiene que establecerse el nuevo decir? ¿A qué cosa tendría él que oponerse o refutar? Pero si efectivamente se trata de una oposición, ¿no sería esta una recaída en la negación determinada de la lógica de la metafísica? En cuanto a la segunda modalidad del decir, el wieder, las cosas tampoco resultan mucho más fáciles. En efecto, ¿qué es lo que tiene que ser dicho otra vez? ¿En qué tipo de repetición piensa Heidegger? Por otra parte, ¿no es la filosofía una indagación libre, sin juicios previos, a la que la idea misma de repetición debiera resultarle ajena? En realidad, solo entendiendo adecuadamente lo que Heidegger busca significar con este 'contra' y este 'otra vez' es que podremos captar el fondo de lo que ha de ser interrogado por la pregunta de fondo (die Grundfrage). Lo que resta de este escrito lo dedicaré a estudiar estas dos vías del pensamiento -en realidad, estas dos direcciones de una vía única: el "desde" (el inicio) y el "hacia” (el inicio).

Como cabía esperar, el "contra" del que habla Heidegger apunta ante todo a un "contra la metafísica". Pero este contra no equivale en ningún caso a rechazarla o a criticarla, y menos aun a negar su (esencial) pertenencia a la historia del ser. No se trata de atacarla como a una filosofía incorrecta, sino todo lo contrario: de tomarla como una verdad que no es lo suficientemente inicial. En este sentido, el "contra" se muestra como lo contrario a lo que en un primer momento pudo haber parecido: en lugar de exponer la falsedad de lo pensado por los pensadores del pasado, lo que está en juego en esta "contra-dicción" es mostrar su carácter de verdad. Pensar "contra" es pensar el pasado con la mayor fidelidad posible, demostrar su pertenencia a una historia común en la cual cada momento es tan verdadero como el resto de los momentos. Pensar "contra" es esencialmente un rememorar, un restituir: "...el desarrollo de la pregunta de fondo suministra simultáneamente [...] el suelo para recuperar el todo de la historia de la pregunta-guía en una posesión originaria, y no, acaso, para desecharla como algo pretérito" (Heidegger 1996/1997, p. 46). Desde este punto de vista, el proyecto de superar la metafísica (o de instalarse en un pensamiento post-metafísico) no tiene nada que ver con un dejar atrás la metafísica como si ella representase un estadio menos desarrollado del pensamiento, pues tal concepción solo sería posible al interior de una consideración metafísica del tiempo (la serie de los "ahoras"), y por tanto volvería a enredarse en aquello que pretendía superar. En la historia del ser no hay progreso sino solo expansión del inicio. Ahora, si bien no hay un "dejar atrás" la metafísica, sí se requiere del pensamiento un "paso atrás" en relación con la metafísica-un paso atrás en el sentido de un abandono de la interpretación metafísica de la metafísica con el fin de 
captar la esencia de la propia metafísica (Heidegger 2000, p. 316). El lector recordará lo que señalábamos hace un momento: la metafísica está constitutivamente imposibilitada para captarse a sí misma de modo esencial. Su carácter inesencial le pertenece a su esencia -solo así participa de la historia del ser. En este punto, es central recordar un aspecto del asunto al que Heidegger le da la mayor importancia, a saber: que una cosa es la historia del ser y otra cosa muy distinta es su captación en tanto que tal. La metafísica está solo en la primera situación, no en la segunda. Pensar de acuerdo a la historia del ser es situarse más allá de la metafísica, pero solo para demostrar que en el fondo se pertenece a lo mismo a lo que ella pertenece: la historia del ser. La metafísica es parte de la historia del ser, y lo es como la época del pensamiento en la que el ser se ocultó y, a su vez, ocultó su ocultamiento. En la metafísica el ser esencia como lo olvidado. En la medida en que un pensador responde a un requisito del ser, ese pensador y lo pensado por él resultan, en cuanto verdaderos, absolutamente irrefutables: al pensar del presente no le queda sino pensar lo pensado en ese pensamiento $-\mathrm{y}$, por cierto, pensar también lo que ha quedado impensado en él y que solo desde otra época en la historia del ser puede ser pensado. Como escribe Eduardo Carrasco, “....cada época de la verdad es también una época de lo que es. Lo que es toma la forma de lo que se piensa; y lo que se piensa toma la forma de lo que es" (2007, p. 114). Es esta histórica copertenencia del ser y el pensar lo que el pensamiento rememorante -aquel que da el salto hacia la historia del ser- debe atravesar o restituir para así abrir una nueva época en la historia del ser. De acuerdo con Heidegger, no es posible el advenimiento de un nuevo tiempo sin la participación de éste del tiempo originario, del tiempo del ser: su historia. Una nueva época no se abre como se abre una utopía, es decir, en una dimensión meramente humana; es el ser-su expansión, su historia- lo que determina lo que ha de ser, sin que ello implique, naturalmente, que el futuro esté ya escrito o predeterminado. Si el concepto de utopía es metafísico de arriba abajo, el pensamiento rememorante ha de presentarse como un pensar que abandona la pretensión humana de hacer de la realidad lo que la voluntad desea, para abrirse en su lugar a una escucha de aquello de lo cual surgen todos los poderes: el ámbito del ser.

Por su parte, el Wieder-spruch -o la nueva-dicción- demuestra que la mutua irrefutabilidad de la que hablábamos, se explica esencialmente por el hecho de que todos los pensadores, precisamente en tanto que pensadores, pertenecen al inicio. Como escribe Heidegger, “....en el fondo siempre se piensa lo mismo y la alternativa irrefutabilidad no mienta la absoluta incompatibilidad, sino solo la señal de que siempre se pregunta lo mismo; lo que sin embargo excluye toda nivelación y debilitamiento" (2003, p. 32). Que siempre se piense lo mismo implica que no existe un pensador más verdadero que otro, pero ello no porque la verdad haya sido eliminada y solo reine en el mundo la opinión, sino porque todos ellos están en la verdad misma-aunque no en la misma verdad- en la medida en que participan de la historia del ser, es decir, de la expansión de lo que los une a todos: el inicio ${ }^{4}$. En este sentido, pensar "contra" la

$4 \quad$ En De la esencia de la verdad, Heidegger ilustra este reinado de la opinión a partir de la incredulidad con la que los habitantes de la caverna reciben a quien se ha aventurado 
historia de la filosofía es pensar la palabra de sus pensadores como un decir que dice "otra vez", como una repetición del inicio. Al interior de la historia del ser, decir algo nuevo (diferencia) es necesariamente decir "de nuevo" (identidad). Si Heidegger afirma que en filosofía el progreso es inesencial, ello se debe a que el inicio no es nunca lo que se queda rezagado por el mero hecho de haber tenido lugar al comienzo de una serie -es decir, lo primero en el ámbito de la temporalidad metafísica-, sino lo que a cada momento está viniendo, aquello que ocurre constantemente como donación bajo la forma de un despliegue de lo inicial. Cuando la verdad pasa a ser concebida como desocultamiento en lugar de adecuación (época del olvido del ser), la historia del pensamiento se transforma completamente: las obras o los sistemas dejan de ser medidos en función de la coherencia interna de sus explicaciones del ente, para ser asumidos en cambio como un descubrimiento o un develamiento de lo que es. El único asunto al que un pensador debe hacer frente es el ser: solo se piensa cuando se sale a su encuentro en el modo en que éste se presenta a lo largo de su historia. Es por este motivo que Ricoeur, desde una posición bastante cercana a la del propio Heidegger, postula que para cada pensador ha de darse una “... relación entre el deber de pensar y una suerte de esperanza ontológica" (68). Frente a la "historia estructural", que reduce la historia del pensamiento al desarrollo de una filosofía o sistema únicos, y también frente a la "historia acontecimental" (Ricoeur), que apuesta por ver a cada pensador como una totalidad cerrada sobre sí misma que carece de relaciones con el resto de los pensadores de la historia, la esperanza ontológica de Ricoeur supone más bien que cada pensador debe "esperar estar en la verdad" - esperar a que en el salto hacia el ser que él ha dado el propio ser se piense a través de o en su palabra. Ahí donde el círculo del ente es atravesado en dirección al ser, todo señorío humano cede y no resta más que el salto, la esperanza, la insistencia extática: en una palabra, el preguntar. Dado que la unidad de la historia no puede nunca "tenerse" -no es un ente del que algún pensador pueda asegurarse-, la apertura que funda la unidad de las preguntas no puede ser apresada o llevada a un enunciado, no puede ser convertida en una respuesta dada de una vez y para siempre: ella se sostiene solo en el preguntar, en la insistente aspiración al ser a la que cada pensador ha de entregarse. "¿Qué significa esta idea de "apertura”? Significa -anota Ricoeur-que las múltiples singularidades filosóficas -Platón, Descartes, Spinoza-son a priori accesibles una a otra, que todo diálogo es posible a priori, porque el ser es ese

más allá de sus límites para luego regresar a liberar a sus compañeros. A él "[s]e le dirá que es unilateral, que, viniendo de alguna parte, tiene a los ojos de ellos una posición contingente y arbitraria [...] se le da a entender que está trabajando con eso que se da en llamar presupuestos de una visión de mundo [...] Aquí, en la caverna (como al fin y al cabo describe Platón), se trata solo de quién es el más astuto y taimado, de quién es el más rápido en adivinar dónde hay que encuadrar, desde sus puntos de vista, todas las sombras que aparecen..." (2007, p. 90). Esta es la escena metafísica (y, en particular, la escena de la metafísica del sujeto) por excelencia: puesto que del ser no hay nada, solo queda entre los hombres la lucha por los "valores", la pugna por el establecimiento de criterios o de medidas unilaterales que expliquen la realidad exclusiva del ente. 
acto que, al preceder y fundar toda posibilidad de preguntar, funda la mutualidad de las intenciones filosóficas más singulares" (2015, p. 68).

Si el ser es como apertura, la tarea del pensamiento es participar de esa apertura, repetir su pertenencia al inicio -repetirlo no como "algo" que se repite, como un inicio que se querría siempre idéntico a sí: en tal caso, ya no habría historia. Para que haya historia, es necesario que ese inicio se expanda, que asuma una dirección: que el preguntar lo repita como diferencia. Puesto que el inicio es irrebasable -todo tiene lugar como su expansión-, cada vez el comienzo comienza. Como dice Heidegger, "[s]olo lo único es re-petible. Solo él tiene en sí el fundamento de la necesidad de que se regresa otra vez a él y se asuma su inicialidad [...] el inicio jamás puede ser aprehendido como el mismo, porque es anticipatorio y sobrecoge así, en cada caso, lo iniciado por él, y determina, en conformidad con ello, la re-petición de sí" (1996/1997, p. 33). Para captar esta difícil relación entre repetición y diferencia, puede que sea útil recurrir a un ejemplo en el que ella se muestra con rasgos un tanto más claros: el de la traducción poética. ¿Cómo traducir el acontecimiento que cada poema representa al interior de una lengua al espacio de otra lengua? ¿Cómo traducir ya no simplemente lo que un poema dice -su literalidad, sus significados-, sino la experiencia originaria a que él dio lugar? El único modo de repetir en la traducción el originario acontecimiento-poema, de volver a poner en marcha lo que él puso en marcha en su lengua de origen, es transformarlo completamente, hacerlo hablar de otro modo para que así diga -o más bien haga- lo mismo. Repetir un poema verbatim es destruirlo en cuanto experiencia poética: la fidelidad a su letra matará su espíritu. No será un poema en la nueva lengua porque no será un acontecimiento al interior de ella. Para que efectivamente sea un poema, solo le resta ser un "nuevo inicio" del original, ser igualmente inicial: ser "nuevo" para ser "de nuevo". De ahí que toda traducción poética entrañe el máximo riesgo: nunca se repiten significados, lo que se repite es una experiencia. En esta repetición, sin embargo, no hay garantía alguna: el traductor solo puede "esperar estar en la verdad" del original, en lo que ha sido abierto por él. Tal es la insuperable dificultad de pensar un "nuevo inicio", tanto para la traducción poética como para el pensamiento del propio Heidegger: solo puedo aspirar a que el ser sea pensado a través de mí.

\section{Referencias bibliográficas}

Adorno, Th. W. (2008), Dialéctica negativa. La jerga de la autenticidad. Obra completa, 6. Tr. Alfredo Brotons Muñoz. Madrid: Ediciones AKAL.

Carrasco, Eduardo (2007), Heidegger y la historia del ser. Santiago: Editorial Universitaria.

Heidegger, Martin (1996/1997), “I. Mirada preliminar (Vorblick)". Contribuciones a la filosofia (Del acontecimiento). Tr. Pablo Oyarzún. Santiago: CONTENIDO. (2007), De la esencia de la verdad. Tr. Alberto Ciria. Barcelona: Herder Editorial. 
(2003), La historia del ser. Tr. Dina V. Picotti C. Ciudad Autónoma de Buenos Aires: El Hilo de Ariadna; Bs. As.: Biblioteca Internacional Martín Heidegger. Destino.

(2000), Nietzsche. Tomo 2. Tr. Juan Luis Vermal. Barcelona: Ediciones (2010), ¿Qué significa pensar? Tr. Raúl Gabás. Madrid: Editorial Trotta.

Hegel, G. W. F. (1966), Fenomenología del espíritu. Tr. Wenceslao Roces. México: Fondo de Cultura Económica.

Ranke, Leopold von (1948), Pueblos y Estados en la Historia Moderna. Tr. Wenceslao Roces. México: Fondo de Cultura Económica.

Ricœur, Paul (2015), Historia y verdad. Tr. Vera Waskman. Buenos Aires: Fondo de Cultura Económica.

Schürmann, Reiner (1996), Des hégémonies brisées. Mauvezin: Trans-Europ-Repress. 